\title{
Stress Coping Mechanism of Children with Learning Disabilities and Effects on Life Satisfaction of Caregivers
}

\author{
Noor Amiera Alias 1, Isma Hanis Ghafar ${ }^{1}$, Azliyana Azizan ${ }^{2}$ \\ ${ }^{1}$ Centre of Occupational Therapy Study, ${ }^{2}$ Centre of Physiotherapy Study, Faculty of Health Sciences, \\ Universiti Teknologi MARA, Bandar Puncak Alam Selangor 42300, Malaysia. \\ Nooramiera@uitm.edu.my, ismahanisghafar@gmail.com ,azliyana9338@uitm.edu.my \\ Tel. 03-32584366
}

\begin{abstract}
The caregiver used variety type of coping mechanism to cope with the challenges in raising children with Learning disabilities (Ld). This study aims to identify the correlation between the coping mechanisms used and life satisfaction. The study found that the reframing $(p=.018)$, acquiring social support ( $p=.006$ )and seeking spiritual support $(p=.041)$ have positive correlation while a passive appraisal $(p=.021)$, has negative correlation with the life satisfaction. Thus, the selected coping mechanisms used may influence caregivers in having a good life satisfaction across the life span subsequently give a positive propensity upbringing childhood with $\mathrm{Ld}$.
\end{abstract}

Keywords: Caregiver;Learning Disability; Coping mechanism; Life Satisfaction

eISSN: 2398-4287 ( 2019. The Authors. Published for AMER ABRA cE-Bs by e-International Publishing House, Ltd., UK. This is an open access article under the CC BYNC-ND license (http://creativecommons.org/licenses/by-nc-nd/4.0/). Peer-review under responsibility of AMER (Association of Malaysian Environment-Behaviour Researchers), ABRA (Association of Behavioural Researchers on Asians) and cE-Bs (Centre for Environment-Behaviour Studies), Faculty of Architecture, Planning \& Surveying, Universiti Teknologi MARA, Malaysia.

DOI: https://doi.org/10.21834/e-bpj.v4i12.1912

\subsection{Introduction}

In recent years, there has been an increasing prevalence child who is having learning disabilities $(\mathrm{Ld})$. It is estimated that the United States notified about $4 \%$ of students of primary school student identified having learning disabilities (Dzalani \& Shamsuddin 2014). Meanwhile, in Malaysia, it was reported there was an increasing number of registered children with learning disabilities within four years in special education class (Ministry of Education, 2014).

The caregiver of children with Ld are vulnerable to psychological distress because dealing with extra demands related to the child's needs, additional expenses that cause burden on family financial and tight schedules (Isa et al. 2014; Noor Amiera \& Akehsan, 2015). Besides, the caregivers also need to be prepared with any uncertainty about the children's medical conditions, child's behaviour, child's adjustment and their futures (Noor Amiera, Akehsan \& Azliyana 2017). Those stress event has been expressed by a caregiver through social isolation, depression and having conflicts in a relationship (Keller \& Honig, 2004). Moreover, previous studies found that the caregivers of children with learning disabilities have higher rates of stress compared to the caregivers of typical children (Dabrowska \& Pisula, 2010; Merkaj et al. 2013). It is found that higher stress level in the caregivers might increase susceptibility to stress-induced illness which will affect the adjustment to taking care of their child with Ld (Siti Nor Ismalina et al., 2016). Hence, those caregivers may require a correct coping mechanism to ensure their necessary life functions to survive.

Previously, it has found that many caregivers can cope and adapt to stress positively (Durban et al., 2012). It may relate to various types of coping strategies that might be used by a caregiver to cope with physical and psychological distress. It is believed that the

eISSN: 2398-4287 (C) 2019. The Authors. Published for AMER ABRA cE-Bs by e-International Publishing House, Ltd., UK. This is an open access article under the CC BYNC-ND license (http://creativecommons.org/licenses/by-nc-nd/4.0/). Peer-review under responsibility of AMER (Association of Malaysian Environment-Behaviour Researchers), ABRA (Association of Behavioural Researchers on Asians) and cE-Bs (Centre for Environment-Behaviour Studies), Faculty of Architecture, Planning \& Surveying, Universiti Teknologi MARA, Malaysia. DOI: https://doi.org/10.21834/e-bpj.v4i12.1912 
nature of coping mechanism used may influence life satisfaction, which later affects the child's future development. Therefore, this study aims to identify the correlation between the coping mechanism used by caregivers and their life satisfaction in having children with Ld.

\subsection{Literature Review}

The most widely accepted theory about stress and the coping process is known as The Transactional Theory of Stress and Coping (Lazarus \& Folkman, 1984). This theory highlighted the process of stress and way to cope with the stress. Both of these two instruments focus on the two types of coping (problem-focus and emotion-focus). Coping often known of its ability to decrease adverse outcomes Heffer \& Willoughby (2017). It is a process that it changes over time whereby a person may use an emotion-focused mechanism and then shift to a problem-focused mechanism or vice versa (Shadiya, 2015). The variety used of coping mechanisms depends on the individuals, which inanition to that problems leads individuals to use different coping strategies in a different situation. It is also indicated that coping includes behaviour and thoughts employed by the individual to manage the stressing situation (Sacchi, 2000).

However, this study focus coping mechanism that covered in F-Copes questionnaire includes acquiring social support, reframing, seeking spiritual support, mobilizing to acquire and accept help, and passive appraisal. The reframing mechanism was found to be associated with significantly related to decrease stress and increase parental wellness (Minnes et al. 2015; Benson, 2010). In another study, found that acquiring social support is one of the coping mechanisms could influence life satisfaction (Ha et al., 2011). The caregiver who does not receive sufficient social support may relate to psychological issue (Chien and Lee, 2013) while the caregiver who received family support can be associated with positive cognitive, proper social functioning (Marchal et al. 2013). It is resulting should be able to cope better and the high quality of life of the caregiver (Hatzmann et a. 2009). In other study was found the religion is a significant source when dealing with stress which passive appraisal was a lousy mechanism that causes a person to give up facing the problems in life easily (Isa et al., 2016). This type of coping mechanism will give abundantly of negative impacts to the caregiver such as family maladaptation, depression, spousal isolation relationship (Dunn et al. 2001), negative emotion, poor mental health (Mausbach et al. 2013). Conversely, it is agreed that the passive appraisal useful for the short term as to give proper release when faced with a stressor (Azman et al. 2017); Dickson et al., 2012).

Life satisfaction generally can be defined as the individual appraisal about their overall life (Sangeun \& Sang, 2014). As a caregiver, life satisfaction is essential as it can affect the burden and as well as the efficacy of the coping mechanism. There are findings reported that increase satisfaction in life contributes positively in general wellbeing, mood and emotions (Pasupuleti et al. 2009). Additionally, for those who have high life satisfaction also reported more efficient, creative and open-minded in their work (Pasupuleti et al. 2009). Previously, there is study found that excellent coping strategies can reduce the caregiver's burden and finally will increase their life satisfaction (Didiane, 2013). Besides, a study by Dubey and Agarwal (2007) also have determined that there is a relationship between stress coping strategies and life satisfaction.

Moreover, the use of active coping strategies showed useful to promote the high level of life satisfaction not just for instant satisfaction but also be a predictor of life satisfaction for the future. Life satisfaction is very crucial, and it is an essential indicator of positive wellbeing. Some researchers have proven that the caregiver's coping mechanism can be a predictor of their life satisfaction (Tamini \&Ansari, 2014; Salas et al., 2017).

\subsection{Method}

This study is a cross-sectional study which was conducted at three Community Based Rehabilitation (CBR) centre which located in area Air Puteh, Telok Bahang and Permatang Dasar Laut, Pulau Pinang, Malaysia. The purposive sampling method used to recruit caregivers as participants in this study. Sixty-four participants were chosen according to the inclusion and exclusion criteria. The inclusion criteria are included primary caregivers has children with learning disabilities in the range five years to 18 years old, and children are staying at home together with the caregiver. The caregiver also should have no mental health issues and able to read and understand the English language. Meanwhile, the participants who do not meet the inclusion criteria have been excluded. This study obtained ethics approval from UiTM Research Ethics Committee.

Three questionnaires, including socio-demographic, F-COPES and SWLS, were used in this study. The Family Crisis Oriented Personal Evaluation Scales (F-COPES) has 30 items, and it is a self-report questionnaire which the caregiver responded by using 5point Likert Scale. There are five subscales available that are acquiring social support, reframing, seeking spiritual support, mobilizing family to acquire and seek help and passive appraisal. For each subscale, the score for all items will, and the higher score between subscales indicates main strategies used by the caregivers and shows more positive coping and problem-solving strategies during confronting with the stress situation in life.

The Satisfaction With Life Scale (SWLS) is an instrument that has a 5-item scales and also using a Likert scale that ranges from 7 strongly agree to 1 strongly disagree. The highest score indicated that the participants have greater life satisfaction.

\subsection{Results}

The participants consist of a caregiver who is having children with LD: 42 (65.6\%) were female, and 22 (34.4\%) were male. The range age $41-50$ was the highest (38\%), followed by $36-40(22 \%)$. The range age $25-30$ and $30-35$ had the same percentage (19\%) while the least range of the participants in this study was above 50 years old (3.1\%). Concerning the occupation, most of the participants were 
housewife/househusband (44\%) followed by government servant (19\%), private and other (16\%). The participants who self-employed showed the least percentage (6\%). Concerning the income, the participant's salary's range was RM 2001 - RM3000 (34\%) and less than RM 900 (33\%). Other than that, followed by RM 1001 - RM2000 (19\%), RM 900 - RM 1000 (11\%) and the least was the participants who had income RM 3001 and above (3.1\%). As regards the education level, most of the participants were secondarily level $(81 \%)$ followed by college/university $(19 \%)$. The majority of the participants reported that they have only one child with a learning disability $(81 \%)$ followed by two children (13\%), three and four (3.1\%) children with a learning disability. The descriptive analysis for the demographic data also reported that most of the participants have LD children with the age range 8-12 (47\%) followed by 5-7 (31\%), 13-15 (19\%) and more than 15 years old (3\%). Demographic data shows at Table 1.

Table 1: Demographic data $(\mathrm{N}=64)$

\begin{tabular}{|c|c|c|}
\hline Demographic & $\mathrm{N}$ & $\%$ \\
\hline \multicolumn{3}{|l|}{ Parent } \\
\hline Male & 22 & 34.4 \\
\hline Female & 42 & 65.6 \\
\hline \multicolumn{3}{|l|}{ Age } \\
\hline $25-30$ & 12 & 18.8 \\
\hline $30-35$ & 12 & 18.8 \\
\hline $36-40$ & 14 & 21.9 \\
\hline $41-50$ & 24 & 37.5 \\
\hline Above 50 & 2 & 3.1 \\
\hline \multicolumn{3}{|l|}{ Occupation } \\
\hline Self employed & 4 & 6.3 \\
\hline Private & 10 & 15.6 \\
\hline Goverment & 12 & 18.8 \\
\hline Housewife/Househusband & 28 & 43.8 \\
\hline Others & 10 & 15.6 \\
\hline \multicolumn{3}{|l|}{ Salary } \\
\hline Less than RM 900 & 21 & 32.8 \\
\hline RM 900 - RM 1000 & 7 & 10.9 \\
\hline RM 1001 - RM 2000 & 12 & 18.8 \\
\hline RM 2001 - RM 3000 & 22 & 34.4 \\
\hline RM 3001 and above & 2 & 3.1 \\
\hline \multicolumn{3}{|l|}{ Education level } \\
\hline None & 0 & 0 \\
\hline Primary & 0 & 0 \\
\hline Secondary & 52 & 81.3 \\
\hline College/University & 12 & 18.8 \\
\hline \multicolumn{3}{|l|}{ Number of children with LD } \\
\hline One & 52 & 81.3 \\
\hline Two & 8 & 12.5 \\
\hline Three & 2 & 3.1 \\
\hline Four & 2 & 3.1 \\
\hline \multicolumn{3}{|l|}{ Child's Age } \\
\hline $5-7$ & 20 & 31.3 \\
\hline $8-12$ & 30 & 46.9 \\
\hline $13-15$ & 12 & 18.8 \\
\hline$>15$ & 2 & 3.2 \\
\hline
\end{tabular}

Each subscale of coping mechanism in F-COPES was summarized to determine the mechanism used by the caregivers. Among the five subscales, the most coping mechanism used by the caregivers was reframing $(M=32.19, S D=4.38)$ followed by acquiring social support $(M=29.19, S D=6.55)$. The third highest coping mechanism that utilized by the caregiver was mobilizing family to acquire and accept help ( $M=15.34, S D=3.12$ ) while closely followed by spiritual support $(M=15.0, S D=2.24)$. The least coping mechanism that utilized by the caregiver was passive appraisal $(M=10.44, S D=2.40$ ). Table 2 shows the summarization of descriptive analyses for the coping mechanism. The use of coping strategies shows at Table 2.

Table 2 : The use of coping strategies

\begin{tabular}{lcc}
\hline \multicolumn{1}{c}{ Subscales } & Mean & Standard Deviation \\
\hline Acquiring Social Support & 29.19 & 6.549 \\
Reframing & 32.19 & 4.382 \\
Spiritual Support & 15.0 & 2.240
\end{tabular}


The Satisfaction With Life Scale (SWLS) was used to identify the caregiver's life satisfaction. Throughout the analysis, it was found that the overall scoring $(M=24.28, S D=5.412)$ for life satisfaction shows that the caregivers were satisfied with their life.

Table 3: Frequency Level Satisfaction of Life

\begin{tabular}{ccc}
\hline Scoring & Mean & Standard Deviation \\
\hline Overall Satisfaction of Life & 24.28 & 5.412 \\
\hline
\end{tabular}

The study found that the reframing $(r(62)=.186, p=.018)$, acquiring social support $(r(62)=.339, p=.006)$ and seeking spiritual support $(r(62)=.257, p=.041)$ have positive correlation in a meanwhile a passive appraisal $(r(62)=-.288, p=.021)$, has negative correlation with the life satisfaction. It is shows in Table 4.

Table 4: Correlation Analysis Between Subscale Of Coping Mechanism And The Life Satisfaction

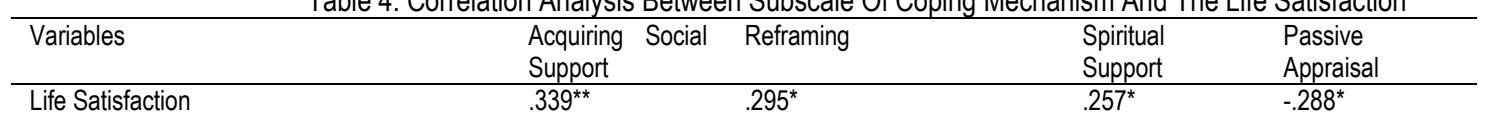

\subsection{Discussion}

This study highlighted there was a positive and negative correlation between coping mechanism and life satisfaction. There were three subscales of the coping mechanism shows a significant positive correlation to life satisfaction, including acquiring social support which indicated a positive correlation, both reframing and spiritual support mechanism showed a positive correlation. This finding in line with a previous result which the caregiver's well being associated with the acquiring social support from others. It may because the participant receives a good support system from spouse since most of the participants are married as well as they may parents from the same CBR which most likely facing the same challenges. They may change and sharing the same sadness, stressful and problems that make them supporting each other. Consistently, a study done by Borg \& Hallberg (2006) found that common factor of less satisfaction among frequent caregivers had low social resources. Thus, it is suggested that the caregiver to expose and get more relationship with others which resulting them to have good life satisfaction.

As reframing significantly related to life satisfaction and the finding also agreed by others study such as a study by lsa et al. (2016); Pakenham \& Bursnall, 2006). Moreover, several studies also claimed that reframing correlates with the caregiver's wellbeing and reduce parental stress (Minnes et al. 2015; Pakenham \& Bursnall, 2006; Benson, 2010). Again this correlation can also be proven by actual meeting with caregiver in CBR where most of them were very supportive of each other and optimistic. They were very cooperative to participated in this study and being optimistic about answering the questionnaire. It is referred to the person who always will try their best to reframe stressor in their life into positive thought that drives them for active coping strategy such as problem-solving and seeking help from others.

In this study, not just social support and reframing, but spiritual support also significantly correlates with life satisfaction. As ones who have a belief to God, when struggling with many obstacles and stressful event, we always will return to our Creator, pray to Him and seeking His mercy. All these will give comfort and strength to the people because they believe good things happen for a reason(Noor Amiera \& Akehsan, 2014). In line with this, it is believed that religion is a significant source of Malaysian when dealing with stress (Isa et al., 2016). For Muslim, the concept of 'redha' which accept all events that happen in our life will make the caregiver subsequently be more faithful to God together with life satisfaction fulfilled.

Nonetheless, passive appraisal shows negative correlation towards life satisfaction, which indicates that the more the caregiver avoid the problems, the less satisfaction they will feel in their life. Previously, it is supported by Isa et al. (2016) who found that this kind of mechanism was a not encourage to use that mechanism which makes the person give up to solve the problems quickly and this indicates higher stress level among those caregivers who were using this mechanism. Moreover, this type of coping mechanism will give abundantly of negative impacts to the caregiver such as family maladaptation, depression, spousal isolation relationship (Dunn et al. 2001), negative emotion (Ruiz \& Moya, 2013), poor mental health (Mausbach et al. 2013; Benson, 2010). Leisure activities to divert the problems temporarily and even crying were helpful to release the emotion that keeps internally. It indicates that which that avoidant mechanism was excellent and can give proper release for a person is facing many obstacles in life (Azman et al. (2017); Dickson et al. (2012).

However, life satisfaction is also affected negatively by the caregiver's role when other households, physical, less sleep, economic constraint, and psychological needs are not fulfilled (Arango et al. 2010). Thus, the caregiver will have a more favourable outcome in overall life satisfaction when encouraged towards their parental roles towards the children (MacDonald \& Hastings, 2010). Therefore, 
an Occupational therapist should concern for proactive strategies to improve the caregiver to reduce stress, increase correct coping mechanism and provides necessary assistance needed by the caregivers.

\subsection{Conclusion \& Recommendations}

Generally, due to some limitation such as small sample size and limited socioeconomic classes in this study, all the finding limited to generalization. It is recommended a larger sample size and take into account to be more random with a different population such as urban setting or higher socioeconomic populations so that the finding can be generalized. The qualitative measurement is strongly recommended to incorporate into prospective research so that may provide more information and more in-depth understanding of caregiver's coping mechanism and their life satisfaction.

In conclusion, this study indicates that the coping mechanism that may cause significant correlate positively with the life satisfaction including acquiring social support, reframing and spiritual support despite passive appraisal may have a negative correlation with life satisfaction. However, finding from this study should be able highlighted that the selection coping mechanism acquiring social support, reframing and spiritual support give a positive influence on life satisfaction. This study should be able to increase their awareness so that the community have a better understanding and decrease psychological distress issues. Besides, as psychological distress may cause by various reasons, hence the higher authority related to this issue such as policymaker on financial, medical service and education needs to be concern more about the caregiver so that their life satisfaction and quality of life better. Therefore, the health professional should be able improves the programs and resources so that neither children nor caregiver earn the benefits.

\section{References}

Arango-Lasprilla, J.C., Plaza, S.L., Drew, A., Romero, J.L., Pizarro, J.A., Francis, K., \& Kreutzer, J. (2010). Family needs and psychosocial functioning of caregivers of individuals with spinal cord injury from Colombia, South America. NeuroRehabilitation. 27(1), 83-93.

Azman, A., Jamir Singh, P. S., \& Sulaiman, J. (2017). Caregiver coping with the mentally ill: a qualitative study. Journal of Mental Health, 26(2), 98-103.

Benson, P. R. (2010). Coping, distress, and well-being in mothers of children with autism. Research in Autism Spectrum Disorders, 4(2), 217-228

Borg, C., \& Hallberg IR. (2006). Life satisfaction among informal caregivers in comparison with non-caregivers. Scand J Caring Sci., 20(4):427-38.

Chien, W. T., \& Lee, I. Y. (2013). An exploratory study of parents' perceived educational needs for parenting a child with learning disabilities. Asian Nursing Research $7(1), 16-25$

Cramm, J. M., \& Nieboer, A. P. (2011). Psychological well-being of caregivers of children with intellectual disabilities: Using parental stress as a mediating factor. Journal of Intellectual Disabilities, 15(2), 101-113.

Dabrowska, A., \& Pisula, E. (2010). Parenting stress and coping styles in mothers and fathers of pre-school children with autism and Down syndrome. Journal of Intellectual Disability Research, 54(3), 266-280.

Dickson, A., O'Brien, G., Ward, R., Flowers, P., Allan, D., \& O'Carroll, R. (2012). Adjustment and coping in spousal caregivers following a traumatic spinal cord injury: An interpretative phenomenological analysis. Journal of health psychology, 17(2), 247-257.

Didiana, D. L. S. (2013). Correlations among coping skills and life satisfaction in ethnic older caregivers

Diener, E. D., Emmons, R. A., Larsen, R. J., \& Griffin, S. (1985). The satisfaction with life scale. Journal of personality assessment, 49(1), 71-75.

Durban, J. M., Rodriguez-Pabayos, A. M., Alontaga, J. V., Dolorfino-Arreza, G., \& Salazar, C. (2012). Coping strategies of parents of children with developmental delay: a quantitative analysis. Asian journal of social sciences \& humanities, 1(4), 177-195.

Dubey, A., \& Agarwal, A. (2007). Coping strategies and life satisfaction: Chronically ill patients' perspectives. Journal of the Indian Academy of Applied Psychology, 33(2) $161-168$

Dunn, M. E., Burbine, T., Bowers, C. A., \& Tantleff-Dunn, S. (2001). Moderators of stress in parents of children with autism. Community mental health journal, 37(1), 3952

Dzalani, H., \& Shamsuddin, K. (2014). A Review of Definitions and Identifications of Specific Learning Disabilities in Malaysia and Challenges in Provision of Services. Pertanika Journal of Social Sciences \& Humanities, 22(1).

Folkman, S., \& Lazarus, R. S. (1988). Coping as a mediator of emotion. Journal of personality and social psychology, $54(3), 466$.

Ha, J. H., Hong, J., Seltzer, M. M., \& Greenberg, J. S. (2008). Age and gender differences in the well-being of midlife and aging parents with children with mental health or developmental problems: Report of a national study. Journal of health and social behavior, 49(3), 301-316

Hatzmann, J., Maurice-Stam, H., Heymans, H. S., \& Grootenhuis, M. A. (2009). A predictive model of health related quality of life of parents of chronically ill children: the importance of care-dependency of their child and their support system. Health and quality of life outcomes, 7(1), 72

Heffer, T. \& Willoughby, T. (2017). A count of coping strategies: A longitudinal study investigating an alternative method to understanding coping and adjustment. PLoS ONE 12(10). 
Isa, S. N. I., Ishak, I., Ab Rahman, A., Saat, N. Z. M., Din, N. C., Lubis, S. H., \& Ismail, M. F. M. (2016). Perceived Stress among Malay Caregivers of Children with Learning Disabilities in Kelantan. Jurnal Sains Kesihatan Malaysia (Malaysian Journal of Health Sciences), 14(2).

Macdonald, E.E. \& Hastings, R.P. (2010).Mindful Parenting and Care Involvement of Fathers of Children with Intellectual Disabilities. Journal of Child and Family Studies, Vol 19(2), pp 236-240.

Marchal, J. P., Maurice-Stam, H., Hatzmann, J., van Trotsenburg, A. P., \& Grootenhuis, M. A. (2013). Health related quality of life in parents of six to eight year old children with Down syndrome. Research in developmental disabilities, 34(11), 4239-4247.

Mausbach, B. T., Chattillion, E. A., Roepke, S. K., Patterson, T. L., \& Grant, I. (2013). A comparison of psychosocial outcomes in elderly Alzheimer caregivers and noncaregivers. The American Journal of Geriatric Psychiatry, 21(1), 5-13.

Merkaj, V., Kika, M., \& Simaku, A. (2013). Symptoms of stress, depression and anxiety between parents of autistic children and parents of tipically developing children. Academic Journal of Interdisciplinary Studies, 2(2), 345

Minnes, P., Perry, A., \& Weiss, J. A. (2015). Predictors of distress and well-being in parents of young children with developmental delays and disabilities: the importance of parent perceptions. Journal of Intellectual Disability Research, 59(6), 551-560.

Ministry of education (2014). Data Pendidikan khas.

Noor Amiera Alias \& Akehsan Dahlan (2015). Enduring Difficulties: The Challenges of Mothers in Raising Children with Dyslexia. Procedia - Social and Behavioral Sciences, Vol 202, Pages 107-11.

Noor Amiera Alias, Akehsan Dahlan \& Azliyana Azizan (2017) . "I have faith...": An Exploration of Hopefulness in Providing Care for Children with Spesific Learning Difficulties (SpLD). Environment - Behaviour Proceedings Journa, Vol 2(6), 3-9.

Sacchi, M., (2000), FX ARMA filters: 70th Annual International Meeting, SEG, Expanded Abstracts, 2092-209

Siti Nor Ismalina Isa, Ismarulyusda Ishak, Azriani Ab Rahman, Nur Zakiah Mohd Saat, Normah Che Din, Syarif Husin Lubis \& Muhammad Faiz Mohd Ismail (2016). Perceived Stress Among Malay Caregivers Of Children With Learning Disabilities In Kelantan. Jurnal Sains Kesihatan Malaysia, 14(2) , 69-77.

Pasupuleti, S., Allen, R. I., Lambert, E. G., \& Cluse-Tolar, T. (2009). The impact of work stressors on the life satisfaction of social service workers: A preliminary study. Administration in Social Work, 33(3), 319-339.

Pakenham, K. I., Bursnall, S., Chiu, J., Cannon, T., \& Okochi, M. (2006). The psychosocial impact of caregiving on young people who have a parent with an illness or disability: Comparisons between young caregivers and noncaregivers. Rehabilitation Psychology, 51(2), 113.

Ruiz-Robledillo, N., De Andrés-García, S., Pérez-Blasco, J., González-Bono, E., \& Moya-Albiol, L. (2014). Highly resilient coping entails better perceived health, high social support and low morning cortisol levels in parents of children with autism spectrum disorder. Research in Developmental Disabilities, 35(3), 686-695.

Salas, L.B., Rodriguez, V. Y., Urbieta, T.C., \& Esther Cuadrado, E. (2017). The role of coping strategies and self-effi cacy as predictors of life satisfaction in a sample of parents of children with autism spectrum disorder. Psicothema, Vol 29 (1), 55-6.

Sangeun, C \& Sang, K.K (2014). Predictors of life satisfaction among caregivers of children developmental disabilities. Asian Social Science, Vol 11 (2)

Shadiya Mohamed Saleh Baqutayan (2015). Stress and Coping Mechanisms: A Historical Overview. Mediterranean Journal of Social Sciences. Vol 6 No 2.

Tamini, K. B. \& Ansari, A. (2014). Relationship of Stress Coping Strategies and Life Satisfaction among Student. International Journal of Psychology. Vol. 8 (1).

Werner, S., \& Shulman, C. (2013). Subjective well-being among family caregivers of individuals with developmental disabilities: the role of affiliate stigma and psychosocial moderating variables. Research in Developmental Disabilities, 34(11), 4103-4114. 